\title{
SOBRE EL CONCEPTO DE VICIO REDHIBITORIO EN LA COMPRAVENTA. ANÁLISIS COMPARADO DE LA JURISPRUDENCIA CHILENA Y COLOMBIANA
}

\author{
ON THE CONCEPT REDHIBITORY VICES IN THE CONTRACT OF \\ SALE. CHILEAN AND COLOMBIAN CASE LAW COMPARATIVE \\ ANALYSIS
}

JORGE OVIEDO ALBÁN*

\begin{abstract}
RESUMEN: El Código Civil de Colombia y Chile consagra la obligación de saneamiento por vicios ocultos de la cosa objeto del contrato de venta. Las normas respectivas señalan los requisitos para que los vicios generen la acción redhibitoria. No obstante, en la ley y la doctrina no se encuentra una propuesta acerca del concepto propio de vicio y tampoco una categorización sistemática de ellos a pesar de que este constituye el supuesto de hecho básico para que proceda la acción redhibitoria. Este trabajo explora, a partir del análisis comparado de decisiones judiciales, una posible conceptualización y sistematización de los defectos que hacen que el objeto del contrato de venta adolezca o no de vicios redhibitorios. Igualmente se estudian los casos dudosos que pueden dar lugar tanto a una acción redhibitoria como a una acción de nulidad por error en el objeto.
\end{abstract}

Palabras clave: vicios redhibitorios, acción redhibitoria, compraventa.

ABSTRACT: The Civil Code of Colombia and Chile, regulate the obligation of liability for latent defects of the thing which the contract of sale. Respective norms, governing the requirements for point defects generated rescission action. However, the law and authors is not a proposal about the concept itself of vice nor systematic categorization of them even though it constitutes the basic assumption made for appropriate action rescission. This paper explores, from the comparative analysis of judicial decisions possible conceptualization and systematization of the defects that make the contract of sale of tainted or hidden defect. Also explores the borderline cases that can lead both to a rescission action as a nullity action in the object by mistake.

Key words: Redhibitory vices, rescission action, contract of sale.

\section{INTRODUCCIÓN}

Como es sabido, los Códigos Civiles de Chile (1855) y de Colombia (1887) son y permanecen sustancialmente idénticos en materia de obligaciones y contratos. No es de

\footnotetext{
* Licenciado en Derecho por la Pontificia Universidad Javeriana de Bogotá. Especialista en Derecho Comercial por la misma Universidad. Abogado. Doctorando en Derecho Universidad de los Andes de Chile. Profesor de Derecho Civil y Jefe del Área de Derecho Privado y de la Empresa en la Facultad de Derecho de la Universidad de la Sabana (Colombia). Dirección: Universidad de la Sabana, Campus del puente del común, Autopista norte km 21 Bogotá D.C. Correo electrónico: jorge.oviedo@unisabana.edu.co
} 
extrañar, por tanto, que en ambos se establezca que el vendedor, además de quedar obligado para con el comprador a la tradición y entrega de la cosa, es responsable del saneamiento, que comprende dos objetos: la evicción y los vicios ocultos o redhibitorios (artículos 1893 del Código Civil colombiano y 1837 del Código Civil chileno, en adelante C.C. col., y C.C. chil., respectivamente). En ambos Códigos, la presencia de estos vicios en la cosa mueble o inmueble objeto del contrato concede al comprador una acción para pedir alternativamente que se "rescinda" la venta (acción redhibitoria), o se rebaje el precio proporcionalmente (acción estimatoria o quanti minoris), (artículos 1914 C.C. col. y 1857 C.C. chil.).

Para que proceda la responsabilidad redhibitoria los artículos 1915 C.C. col. y 1858 C.C. chil., determinan los requisitos que deben cumplir dichos vicios: haber existido al tiempo de la venta; ser tales que por ellos la cosa vendida no sirva o solo sirva imperfectamente para su uso natural de forma que si el comprador los hubiese conocido no la habría comprado o lo hubiera hecho a mucho menos precio y ser ocultos, por lo menos para el comprador ${ }^{1}$.

El concepto nuclear para que pueda hablarse propiamente de "vicios" está en la segunda exigencia: "Ser tales, que por ellos la cosa vendida no sirva para su uso natural, o solo sirva imperfectamente, de manera que sea de presumir que conociéndolos el comprador no la hubiera comprado o la hubiera comprado a mucho menos precio". El que el vicio haya sido anterior a la venta y que el comprador no los haya podido conocer (ocultos) son elementos concurrentes que permiten que el defecto ya considerado como vicio pueda producir la obligación del vendedor de sanearlo, ya sea por la rescisión del contrato o por la reducción del precio.

\footnotetext{
${ }^{1}$ En ambos códigos, el texto normativo citado establece:

"Son vicios redhibitorios los que reúnen las calidades siguientes:

$1^{\text {a }}$. Haber existido al tiempo de la venta;

$2^{\text {a }}$. Ser tales, que por ellos la cosa vendida no sirva para su uso natural, o solo sirva imperfectamente, de manera que sea de presumir que conociéndolos el comprador no la hubiera comprado o la hubiera comprado a mucho menos precio;

$3^{a}$. No haberlos manifestado el vendedor, y ser tales que el comprador haya podido ignorarlos sin negligencia grave de su parte, o tales que el comprador no haya podido fácilmente conocerlos en razón de su profesión u oficio".

El artículo 934 del Código de Comercio colombiano también consagra la acción de saneamiento por vicios redhibitorios. El artículo dispone:

"Si la cosa vendida presenta, con posterioridad a su entrega, vicios o defectos ocultos cuya causa sea anterior al contrato, ignorados sin culpa por el comprador, que hagan la cosa impropia para su natural destinación o para el fin previsto en el contrato, el comprador tendrá derecho a pedir la resolución del mismo o la rebaja del precio a justa tasación. Si el comprador opta por la resolución deberá restituir la cosa al vendedor.

En uno u otro caso habrá lugar a indemnización de perjuicios por parte del vendedor, si este conocía o debía conocer al tiempo del contrato el vicio o el defecto de la cosa vendida”.

Por su parte, el Código de Comercio chileno hace una remisión a las normas del Código Civil, de la siguiente forma: "Artículo 154. El vendedor está obligado a sanear las mercaderías vendidas y a responder de los vicios ocultos que contengan, conforme a las reglas establecidas en el Título De la compraventa del Código Civil.

Las acciones redhibitorias prescribirán por el lapso de seis meses contados desde el día de la entrega real de la cosa".
} 
Sobre el particular cabe señalar que tanto la doctrina chilena como colombiana, ha centrado su atención en la descripción y análisis de los mencionados requisitos normativos y la mención por vía de ejemplo de algunos casos considerados como vicios por los tribunales. No obstante, en los autores no se encuentra una propuesta acerca del concepto propio de vicio y tampoco una categorización sistemática de ellos, a pesar de que este constituye el supuesto de hecho básico para que junto a los requisitos enunciados, proceda la acción redhibitoria ${ }^{2}$.

Esto justifica una indagación que permita establecer cómo se entienden y aplican los criterios normativos que conceptualizan el vicio como tal por parte de tribunales que, partiendo del mismo texto legal, se han enfrentado a realidades y casos diferentes. Por ello, las preguntas a las que pretende responder este artículo son: ¿Cuáles son los defectos que, según los tribunales chilenos y colombianos, hacen que la cosa objeto del contrato de venta adolezca de vicios redhibitorios? ¿Hay coincidencia en la interpretación de los criterios legales o bien diferencias de apreciación?

En la preparación de este trabajo hemos utilizado un método inductivo a partir de la consulta de fallos colombo-chilenos desde el siglo XIX hasta la actualidad y comparativo, tratando de establecer las similitudes y diferencias entre los argumentos y conclusiones de la jurisprudencia de ambos países, para finalmente exponer los casos de manera sistemática ${ }^{3}$.

\footnotetext{
${ }^{2}$ En Chile, el autor que más se ha acercado al punto es Alessandri, al describir algunos fallos antiguos y las conclusiones a las que los tribunales llegaron en su momento al calificar algunas situaciones como vicio, pero sin estructurar las categorías sistemáticamente. ALESSANDRI (1918) pp. 258-260. De la misma forma en Colombia CÁrdenas (2007) p. 218. El autor, al señalar la posibilidad de conceptualizar al vicio como material, en la medida en que la sola presencia del defecto hace que la cosa se considere viciada, o funcional, según la cual el vicio debe afectar la función a que está destinada la cosa, indica en la jurisprudencia colombiana no hay una pronunciación expresa sobre ello. Al contrario de esta afirmación, en este trabajo mostraremos que a pesar de no haber pronunciación expresa, del análisis de los fallos se puede determinar qué tipo de concepto es el que acoge la jurisprudencia colombiana lo mismo que la chilena. También GÓMEZ (2008) p. 99, aunque sin indicar categorías típicas de vicios, intenta una definición genérica apoyándose en un elemento material y otro funcional: "Una cosa puede adolecer de vicios o defectos materiales que la inhabiliten para prestar la utilidad que de acuerdo con su naturaleza le corresponde, o que apenas le permiten prestar imperfectamente esa utilidad". Otros autores se centran en la descripción y análisis de los requisitos de los vicios redhibitorios. Vélez (1926) pp. 246-250. PéreZ (1957) p. 368, quien enuncia algunos casos que a su vez toma de otros autores y sugiere un concepto de vicio, sin decir qué entiende por tal, que resulta del parafraseo normativo: "El vicio oculto es, por regla general, aquel que, existiendo al tiempo de la venta y siendo y debiendo ser ignorado por el comprador, hace imperfecta la cosa vendida para su uso natural o contractual, disminuyendo su utilidad o suprimiéndola completamente". RODRíGUEZ (1960) pp. 868-910. VALENCIA (1985) pp. 86-91, quien sin precisar exactamente de qué se trata, los clasifica en corporales o intrínsecos y extrínsecos al referirse a ciertas cualidades especiales que se aseguran en la cosa que corresponden a los vicios que son considerados como tales por acuerdo de las partes, conforme al artículo 1920 del Código Civil. Más recientemente, TAMAYO (2004) p. 175 intenta una definición general asumiéndolos como "defectos imperceptibles de la cosa".

${ }^{3}$ En el caso colombiano hemos buscado solamente los fallos dictados por la Corte Suprema de Justicia como tribunal de casación, que además cumple la función de unificar jurisprudencia. Cfr. Artículo 234 Constitución Política; Art. 25 Código de Procedimiento Civil. Corte Constitucional, Sentencia C - 836 de 2001. Es por esto que salvo en eventos de excepción, la doctrina colombiana no suele estudiar los fallos dictados por tribunales de instancias inferiores.
} 
A partir de un análisis jurisprudencial buscamos forjar categorías típicas de características que constituyen vicios redhibitorios y de aquellas que no lo son, además de casos considerados dudosos, calificados así por considerar que el supuesto fáctico puede servir tanto para entablar una acción redhibitoria, como para proteger al comprador por otras vías.

Para categorizar los casos como constitutivos o no de vicio redhibitorio hemos tenido en cuenta la verificación de la presencia o ausencia de elementos comunes y constantes en cada tipo de imperfección, deducidos del análisis jurisprudencial además del tipo de afección presentada. Igualmente, consideramos necesario señalar que en cada categoría, la ubicación numérica no sugiere que exista un orden jerárquico entre ellas.

\section{CASOS QUE CONSTITUYEN VICIOS REDHIBITORIOS}

Para iniciar el análisis, comenzaremos con los casos en los que los tribunales chilenos o colombianos han considerado que ciertos defectos de la cosa pueden ser calificados de vicios redhibitorios.

Advertimos que esta inclusión no necesariamente lleva a predicar la obligación de saneamiento, ya que en ocasiones las Cortes desechan la responsabilidad aunque se haya probado el vicio, por falta de prueba de alguno de los otros requisitos: ser anterior a la venta o haber sido desconocidos u ocultos.

\section{DefeCtos De COMPOSICIÓN}

Puede ocurrir que los componentes del bien presenten fallas y ante ello, como veremos en los casos mencionados a continuación, surja el dilema de si tales defectos hacen que la cosa se considere viciada.

En un antiguo fallo de un juzgado civil de Santiago, se estimó que si la madera con la que estaba fabricado un piano impedía su funcionamiento, este como tal adolecía de un vicio redhibitorio. El comprador alegó en su demanda que por el defecto de la madera el piano no se podía afinar y por ello se hacía inservible. Pidió se resolviera el contrato en caso en que no se le pudiera entregar otro piano, además de indemnizaciones y costas. Sobre la base de un informe pericial, el Juzgado de Santiago consideró que el bien presentaba vicios redhibitorios toda vez que se había construido con madera que no cumplía las calidades requeridas ${ }^{4}$.

En Colombia, aunque no existe una manera uniforme para citar las decisiones judiciales, cuando se trata de fallos de casación dictados por la Corte Suprema de Justicia, una de las formas usadas por la doctrina colombiana es la siguiente: identificación del tribunal y sala de casación, fecha, nombre del magistrado ponente del fallo, número de expediente, número de la Gaceta Judicial donde se publicó el fallo y página de inicio. En caso de no encontrarse publicada se indica: "No publicada en la Gaceta Judicial". La Gaceta Judicial, publicación oficial de difusión de la jurisprudencia, ha dejado de circular desde los años noventa del siglo XX, por lo que los fallos dictados desde esa época, se citan por el número de expediente. Igualmente se suelen citar otras publicaciones no oficiales, de editoriales privadas, como es el caso de la Revista Jurisprudencia y Doctrina, de la editorial Legis.

4 Toledo con Sazy (1861). En el fallo se condenó al demandado a cambiar el piano a la compradora pues él había adquirido este compromiso en caso de que el informe del perito determinare que el piano tenía defectos. 
La Corte de Apelaciones de Santiago en otro fallo, esta vez de 1883, estimó que concurría un vicio redhibitorio en una máquina trilladora que al ser utilizada presentó desperfectos en sus piezas que se fueron rompiendo. La Corte acogió solo parcialmente la demanda ya que no rescindió el contrato, sino que decretó la rebaja de precio. Estimó que el vicio no impedía completamente el uso, sino solo que la cosa sirviera imperfectamente para su uso natural ${ }^{5}$.

En otra situación similar la Corte de Santiago confirmó la sentencia del juez de primera instancia, en la que se consideró que un motor a vapor y una máquina trilladora objeto del contrato de venta, adolecían de vicios redhibitorios consistentes en el mal estado de diversas piezas y desajuste de otras, que ocasionaron que las máquinas no pudieran ser utilizadas ${ }^{6}$.

En otro caso se trataba de la compra de calzado por un comerciante a un fabricante, quien por estar ubicado en el extranjero actuó por medio de un representante en Chile. Con posterioridad a la venta y entrega de los zapatos a los consumidores, se presentaron reclamos de parte de estos al observar que aquellos se deterioraban rápidamente. En el proceso se logró probar que los zapatos adolecían de defectos toda vez que algunos de sus componentes eran materiales inadecuados, como cartón, que no se observaban a la vista, de forma que no servían para su uso natural, razón por la que se consideró que adolecían de vicios redhibitorios y se acogió la pretensión subsidiaria de rebaja de precio $^{7}$.

Igualmente en otro caso reciente se consideró que las fallas en las piezas de un vehículo comprado como nuevo, constituyen vicio oculto si el vehículo no resulta apto para el uso propio y habitual ${ }^{8}$.

En Colombia se han dado casos también de desperfectos en los materiales que repercuten en que se considere viciosa la cosa entera. En un caso relativo a la venta de una máquina para empacar bolsas de harina, el demandante interpuso la acción resolutoria general por incumplimiento del vendedor, consagrada en el artículo 870 del Código de Comercio. Señaló que la máquina presentaba desperfectos en algunas piezas por lo que no empacaba el número de bolsas estimado en el tiempo y con el peso acordado. El

\footnotetext{
5 Solar con Lyon (1883). La Corte, sin mayores fundamentos jurídicos para la decisión, solo decretó la rebaja de precio puesto que el vendedor actuó como agente del fabricante establecido en Inglaterra. Consideramos que esta solución es un tanto caprichosa, pues el factor diferencial para decretar la resolución o la rebaja del precio es, según lo confirma la lectura de los respectivos artículos, que la cosa no sirva o sirva imperfectamente.

${ }^{6}$ Ojeda con Mackin (1887). El fallo decretó la rescisión de la venta del motor a consecuencia de los vicios redhibitorios. En el caso de la trilladora se obligó de todas formas al vendedor a reparar el bien, pues a ello se había comprometido en el contrato. Se consideró que la obligación de reparar asumida por el vendedor sustituye la rescisión o rebaja del precio.

7 El fallo de primera instancia confirmado en apelación consideró que los defectos aludidos no eran de tanta importancia como para decretar la rescisión por lo que solo se decretó la rebaja de precio. Burgos con Strakoch y Sohn (1914).

${ }^{8}$ El comprador demandó la indemnización del daño moral, tras haber agotado la garantía voluntaria sin que las fallas fueran reparadas, conforme a la Ley 19.496. Rocha con Salinas y Fabres S.A. (2007). También en relación con las fallas de un vehículo como vicio redhibitorio: Aravena con Comercial Rupanco Limitada; Inversiones San Ignacio S.A. (2007). Spataris con Sociedad Comercial Automotriz La Portada; Luna (2007).
} 
fallo de primera instancia, confirmado en apelación, acogió la excepción de falta de fundamentos sustantivos de la acción propuesta por considerar que se trataba de una acción redhibitoria que estaba prescrita. La Corte Suprema, en sentencia de casación, consideró que efectivamente se trataba de un supuesto de vicio redhibitorio, por tratarse de defectos que afectaban el uso determinado por los contratantes, conforme con el artículo 934 del Código de Comercio que para el caso había prescrito?

Así entonces, del análisis de los fallos referidos podemos decir que hay vicio redhibitorio de la cosa cuando por causa de defectos de los materiales que componen el bien, se ocasiona un impedimento total o parcial o una restricción para su uso natural. De lo indicado, consideramos conveniente resaltar que son dos los elementos determinantes que resultan del análisis: el primero se refiere a la presencia en el bien de defectos originados en fallas de los materiales que lo componen y el segundo, consistente en que por razón de dichas fallas se reduce o imposibilita el uso natural por lo que se considera que la cosa está viciada, conforme se infiere de los anteriores fallos mencionados. En este punto, existe coincidencia en la interpretación realizada por los tribunales chilenos y colombianos.

\section{DEFECTOS DE CONSTRUCCiÓN O DISEÑO}

Tanto en Colombia como en Chile se ha discutido si los defectos de construcción o diseño de edificaciones constituyen vicio redhibitorio.

La Corte Suprema de Justicia colombiana dictó un fallo en 1945 a propósito del siguiente caso: el comprador demandó al vendedor para que se decretare la rebaja del precio más indemnización de perjuicios por vicios redhibitorios consistentes en defectos de construcción que ocasionaron grietas en los muros y hundimiento de pisos. El juez de primera instancia negó las pretensiones al considerar que se requería como prueba el examen de expertos. En apelación, el Tribunal Superior de Distrito Judicial de Medellín revocó dicho fallo y en su lugar decretó la rebaja del precio e indemnización de los perjuicios sufridos por el comprador. La Corte Suprema confirmó el fallo de apelación y determinó con base en dictamen de peritos, que quedaban demostradas las condiciones para la existencia de vicios redhibitorios consistentes en que el inmueble tenía graves defectos congénitos de construcción anteriores al contrato, que si el comprador los hubiese conocido no hubiera celebrado el negocio o lo hubiera realizado a menos precio $^{10}$.

\footnotetext{
9 Harinera del Valle con Imocon (2005). También otro caso se refirió a los vicios redhibitorios de un automóvil, por fallas en sus piezas. No obstante, se desestimó la acción redhibitoria porque no se consideraron ocultos. Salcedo con Muñoz y Droguería Jaramillo (1955). Igualmente en una permuta de unas máquinas para panadería por una camioneta, donde se consideró que las fallas en unos componentes del bien constituían vicios, porque eran de tal naturaleza que la hacían impropia para su natural destinación. No obstante, el Tribunal de apelación y la Corte Suprema, negaron la acción redhibitoria por considerar que los vicios no eran ocultos para el comprador. Rodríguez con Gutiérrez (1977).

${ }^{10}$ Los vicios de construcción que reconocieron como redhibitorios consistieron en: "Los pisos del corredor estaban construidos sobre un encañado sostenido por canes y estos a su vez, sostenidos sobre tacos de madera, haciéndose consistir el defecto en que siendo los materiales de una permeabilidad muy grande, de poca resistencia y fácil deterioro por la humedad, ceden hasta producirse grietas que ponen en peligro la estabilidad de la construcción; los muros divisorios estaban construidos sobre bases semejantes a los pisos del corredor y por tal deficiencia se produjeron hundimientos y grietas...”. Barrera con Rojas (1945).
} 
En Chile, encontramos un fallo de la Corte de Santiago de 1879 sobre los siguientes hechos: la compradora de una casa interpuso acción redhibitoria contra el vendedor por la existencia de vicios redhibitorios, puesto que algunas paredes divisorias se encontraban desplomadas y ruinosas. En el fallo se consideró que tales defectos constituyen vicios redhibitorios provenientes de la construcción de la casa, por lo cual lo declaró rescindido ${ }^{11}$.

Posteriormente se han presentado demandas por acción redhibitoria, basadas en los defectos de construcción de edificaciones. La jurisprudencia ha sido reiterativa al considerar que constituyen vicios redhibitorios si afectan total o parcialmente el uso del bien ${ }^{12}$.

De esta forma podemos deducir que tanto para la jurisprudencia chilena como para la colombiana, los defectos de construcción de edificaciones que reduzcan o impidan su uso natural, constituyen vicios redhibitorios. En el análisis que efectúan los tribunales, son dos los elementos que se presentan como una constante: el primero, de carácter material, es que la construcción presente defectos estructurales y el segundo, funcional, que como consecuencia de tales defectos, se comprometa la utilidad del bien para el comprador.

${ }^{11}$ El fallo fue confirmado en apelación. Plaza con Astorga (1879).

12 En un fallo de 1882 confirmado en apelación, relativo a la demanda interpuesta por la compradora de unas casas que pretendía la rescisión del contrato por vicios redhibitorios originados con el desplome de las paredes, se decretó la rebaja de precio porque aunque los desplomes exigían reparación, no hacían que el bien fuera inservible para el uso natural. Vidal con Marcoleta (1882). Un fallo de 1932 también se refirió a los defectos de construcción como redhibitorios, pero se rechazó la demanda interpuesta por el comprador de una casa quien alegó como tales la mala construcción del alcantarillado y la falta de cimientos de algunos tabiques. Se negó la demanda por considerar que tales vicios eran de poca importancia. Valencia con Merry del Val (1932). Otro fallo de 1944 se refirió a un caso de una demanda de indemnización de perjuicios por vicios redhibitorios consistentes en graves defectos de construcción. No obstante, la demanda fue negada porque la acción redhibitoria así como la de rebaja de precio estaban prescritas y tanto la primera instancia, como la Corte Suprema en Casación, consideraron que ante ello no cabía interponer de forma directa la acción indemnizatoria. Franjola con Carvallo (1944). También, en otros casos de épocas más recientes se ha considerado que los defectos de construcción constituyen vicio redhibitorio. Politoff con Sociedad Inmobiliaria Ingeco (1998), en el que se decretó la rebaja de precio demanda por vicios redhibitorios consistentes en grietas en los muros, levantamiento de baldosas de la terraza y revenimientos en los muros exteriores que limitaban el uso natural. Vergara con Inversiones Andalién S.A. (2002), en el que se consideró que los defectos originados en su diseño arquitectónico, calidad de construcción, defectos de ventilación y problemas en los ductos y márgenes de seguridad de forma que se impedía su ocupación y arrendamiento a terceros eran vicios aunque no graves por ser reparables, por lo que se decretó la rebaja de precio. Varela y otros con Servicio de Vivienda y Urbanización I Región (2007), en el que se decretó la rescisión al acoger la acción redhibitoria como pretensión subsidiaria por considerar que la construcción presentaba graves defectos, además de la mala calidad del terreno. Jara y otros con San Francisco Ltda. (2007), donde se consideraron vicios redhibitorios los defectos estructurales de construcción del inmueble, en instalaciones y terminaciones. Larzabal con Sociedad Inmobiliaria Talasia Ltda. (2008), en el que se consideró que había vicios redhibitorios por fallas en la construcción de un departamento consistentes en los defectos de ductos de ventilación y suministro de gas que generaban que el departamento en cuestión tuviera una alta cantidad de gas carbónico. Inversiones y Negocios S.A.; Empresa Administradora de Créditos S.A. con Madison Inmobiliaria S.A. (2008), donde se consideró que las instalaciones defectuosas de gas en un departamento, constituyen vicio redhibitorio. En todos los casos citados se consideró que por los vicios se afectaba el uso natural del bien. 


\section{DEFECTOS DE INSUFICIENCIA MATERIAL}

En algunos eventos el bien no produce el resultado natural o el esperado por el comprador por no tener las condiciones suficientes para ello. La cuestión radica entonces en verificar si esto hace que el bien presente un vicio redhibitorio.

En un caso fallado en Colombia en 1991 se dieron los siguientes hechos: se demandó a una sociedad vendedora de un horno industrial, el cual según afirmó la compradora no servía para el fin pactado, que era el sancochado de calado ${ }^{13}$. La demandante pidió se decretara la resolución del contrato más indemnización de perjuicios por incumplimiento de las obligaciones del vendedor, pues el bien no cumplía con las especificaciones aptas para la finalidad que motivó su adquisición. En fallo de primera instancia se decretó la resolución del contrato por incumplimiento, lo que fue confirmado en apelación. La Corte Suprema en casación, consideró que el defecto alegado por el comprador era un vicio redhibitorio dado que el bien no sirvió para el fin pactado por tener una capacidad térmica insuficiente, e interpretó que la acción que había intentado el demandante era la redhibitoria reconocida en el artículo 934 del Código de Comercio colombiano ${ }^{14}$.

En este mismo grupo podemos incluir los casos relacionados a continuación, dado que en ellos también observamos que los vicios redhibitorios consisten en la insuficiencia del bien para producir el resultado esperado.

En Colombia se falló sobre este caso: una empresa compradora de semillas que fue ejecutada por otra empresa vendedora por incumplimiento en el pago del precio, propuso la excepción de contrato no cumplido alegando como vicio redhibitorio que las semillas eran de mala calidad pues no germinaron. El fallo de primera instancia, confirmado en apelación por el Tribunal Superior de Villavicencio, declaró no probadas las excepciones propuestas y condenó a la compradora. El Tribunal no descartó que la no germinación de las semillas por mala calidad constituya un vicio redhibitorio, pero rechazó la excepción del comprador al no encontrarse probado que los vicios fueran anteriores al contrato ${ }^{15}$.

Igualmente en Chile, la Corte de Apelaciones de Santiago en un fallo de 1996 teniendo en cuenta la mala calidad de la semilla alegada por el comprador, consideró que esta se hallaba afectada por un vicio redhibitorio ${ }^{16}$.

${ }^{13}$ El "sancochado de calado", tal como se describe en el fallo, consiste en extraer la humedad a la masa con la que se hacen panes, para pasarla a tostar en un horno diferente.

14 Industria panificadora El Arbolito con Weston (1991).

${ }^{15}$ La Corte Suprema confirmó las consideraciones del Tribunal. La norma sobre la que se apoyaron tanto el Tribunal como la Corte Suprema, fue el artículo 934 del Código de Comercio. M.R. Inversiones con Cooperativa agropecuaria del Meta (1986). Sobre el caso de las semillas que no germinan y en un sentido similar al fallo citado puede verse: Manssur y Abdala con Hernández y Hernández (1988). En otro caso de unas semillas que no germinaron, el demandante pidió indemnización y en subsidio que la demandada “... responda ... por los vicios redhibitorios de las semillas de arroz vendidas al demandante”. La primera instancia desestimó las pretensiones. La sentencia del Tribunal confirmó el fallo. El Tribunal no pudo determinar si la falta de germinación se debió a un vicio de las semillas o a malos manejos de las mismas. La Corte Suprema no casó la sentencia. Vergara con Caja de Crédito Agrario Industrial y Minero (1999).

${ }^{16} \mathrm{La}$ Corte de apelaciones determinó que la actora había pedido en su demanda que se declare el incumplimiento del contrato por la demandada y los perjuicios ocasionados. La Corte consideró que “...puede darse por demostrado que existió tal incumplimiento por parte de la demandada, ya que medió la existencia de un vicio oculto en la cosa vendida". Sobre la base del incumplimiento y al asumir que el vendedor debía conocer los vicios, decretó la indemnización. Viollier Velasco, Fernando con Agricamex Ltda. (1996). 
Como resultado de lo anterior, podemos indicar que en el análisis de los fallos hay dos elementos concurrentes: el primero es la presencia en el bien de un defecto consistente en la insuficiencia técnica o material y el segundo, que como consecuencia de ello el bien no sea idóneo para producir el resultado natural o el que el comprador espera y hace saber al vendedor al momento de celebración del contrato, a partir de todo lo cual tanto los tribunales chilenos como colombianos concluyen que el bien adolece de un vicio redhibitorio ${ }^{17}$.

\section{Defectos DE ELABORACión Y ENVASE}

Durante el proceso de elaboración y envase o empaque del bien, pueden presentarse fallas que estén en capacidad de comprometer su uso, ante lo cual surge la inquietud de si tales defectos constituyen vicio redhibitorio.

Sobre el particular se encuentra el siguiente caso fallado en 1915 por la Corte de Santiago: se celebró un contrato de venta de toda la producción de conservas de alimentos de una determinada fábrica. La empresa compradora fue demandada por el vendedor ante incumplimiento en el pago del precio. La demandada presentó reconvención, señalando que había recibido reclamos de los comerciantes a quienes había revendido las latas de conservas, porque los envases explotaban debido a la fermentación del contenido y pidió que se condenara al vendedor a pagar las indemnizaciones por los perjuicios ocasionados a la parte compradora por la mala calidad de los productos.

El fallo de primera instancia rechazó la demanda y la reconvención al considerar que ambas partes habían incumplido las obligaciones. La Corte de apelaciones consideró que el vicio redhibitorio consistía en defectos en la elaboración de los productos de forma tal que las sustancias envasadas no estaban inalteradas y puras, haciéndolas impropias para su comercialización y consumo ${ }^{18}$.

${ }^{17}$ El artículo 934 del Código de Comercio colombiano es un tanto más amplio que su correspondiente del Código Civil, toda vez que señala que el vicio redhibitorio no solo es el que afecta o disminuye el uso natural, sino también el fin previsto en el contrato. A partir de ello, en el fallo Industria panificadora El Arbolito con Weston (1991), cit., supra, nt. 14, es que se analiza si el vicio afecta el fin que fue convenido por las partes. Lo mismo sucede en el siguiente fallo: Harinera del Valle con Imocon (2005), cit., supra, nt. 9. En Colombia, algunos autores también han señalado que el uso comprometido con el defecto puede ser el pactado. Cfr. PÉrez (1957) p. 368. Rodríguez (1960) p. 885. TAMAYo (2004) pp. 178-179, aunque este último asume que el pacto debe ser expreso. Al revisar la jurisprudencia chilena advertimos que indirectamente se ha hecho alusión a que el vicio puede afectar un uso distinto del natural, al que el comprador pretenda destinar la cosa, siempre y cuando lo haya hecho saber al vendedor. Así se expresó la Corte de Apelaciones de Concepción en un fallo relativo a una acción redhibitoria interpuesta por el comprador de unos departamentos: "De lo anterior resulta que si los departamentos y estacionamientos sirven imperfectamente para otro uso diverso, no adolecen de vicios redhibitorios, salvo que el comprador haga saber al vendedor que la cosa va a ser destinada a un uso diverso y este la vende a sabiendas del uso que le daría el comprador...". Vergara con Inversiones Andalién S.A. (2002), cit., supra, nt. 12. En la doctrina chilena ya ALESSANDRI (1918), p. 273 se pronunció en su momento a favor de esta posibilidad, al considerar que también existe vicio cuando la cosa no sirve para el uso distinto al natural que el comprador hizo saber al vendedor, quien a sabiendas celebró el contrato.

${ }^{18}$ La Corte de Apelaciones decidió de todas formas, que no se había interpuesto la acción redhibitoria o de rebaja de precio y que además por no haberse probado que el vendedor conocía los vicios, no había lugar tampoco a la indemnización de perjuicios. Aceptó la demanda en cuanto a que la compradora debía pagar 
Podemos señalar entonces, como regla derivada de este fallo, que los defectos de elaboración y envase o empaque de los bienes (elemento material) por los que se compromete el uso natural del bien, que es la comercialización y consumo (elemento funcional), constituyen vicios redhibitorios. No hemos encontrado fallos colombianos sobre casos similares.

\section{DEFECTOS DE SALUBRIDAD}

La pregunta que surge en este punto, consiste en determinar si la presencia en el bien de elementos patógenos que estén en capacidad de afectar a las personas que al usarlo se vean expuestos a contraer enfermedades, constituye vicio redhibitorio.

Sobre el particular, encontramos el siguiente caso fallado por los tribunales colombianos: los compradores de un inmueble demandaron la rebaja de precio e indemnización de perjuicios por vicio redhibitorio. El vicio alegado consistió en que la casa vendida estaba infectada pues en ella vivió la hija de los vendedores que sufría de lepra, por lo que no podía ser ocupada por personas sanas. El juzgado séptimo civil del Circuito de Bogotá negó las pretensiones. El Tribunal Superior del Distrito Judicial de Bogotá revocó la sentencia en apelación, decretó la rebaja de precio por vicio redhibitorio y condenó a los demandados a pagar los perjuicios por no haberlo declarado al contratar. El fallo fue confirmado en casación por la Corte Suprema, la que señaló que la enfermedad sufrida por una persona que haya habitado una casa que genere la posibilidad de contagio, constituye vicio redhibitorio ${ }^{19}$.

Así, aunque no hemos encontrado jurisprudencia chilena sobre el particular, podemos deducir que por lo menos para la jurisprudencia colombiana, la presencia de factores patógenos en el bien en capacidad de afectar la salud de las personas que se vean expuestas a ellos al utilizar la cosa, constituye vicio redhibitorio. Nuevamente, como en los casos analizados en los puntos anteriores, advertimos la presencia de dos elementos concurrentes: el primero consiste en el elemento de carácter material generador del vicio y el segundo, que como consecuencia de él la cosa no sirva o sirva imperfectamente para el uso natural.

\section{DEFECTOS DE DESCOMPOSICIÓN O CONTAMINACIÓN}

En algunas ocasiones el bien puede ser afectado por factores externos, como plagas o internos como enfermedades (como en el caso de los animales) y ante ello surge la pregunta de si esto constituye vicio redhibitorio.

\footnotetext{
el precio y desechó las excepciones de caducidad o prescripción de la acción redhibitoria interpuesta por el demandante reconvenido. Rubio con Besa y Compañia (1915). También debe tenerse en cuenta un fallo reciente que consideró como redhibitorios los vicios consistentes en la descomposición de productos de mar originados en la negligencia del vendedor al no observar las medidas de embalaje y preservación de los mismos. En fallo de primera instancia y apelación se decretó la rebaja de precio e indemnización propuestos por el comprador en reconvención ante la demanda del vendedor por incumplimiento en el pago del precio. Importadora Exportadora JYC Ltda. con Comercial Cisandina Chile Ltda. (2005).

${ }_{19}$ Presumió además el conocimiento por parte de los vendedores, al considerar que la enfermedad se había originado mientras la niña habitaba la casa. Vergara y Abadía con Izquierdo e Izquierdo (1943).
} 
En un fallo chileno de 1882 se consideró que la existencia de gorgojo en un cargamento de trigo constituía vicio redhibitorio, aunque sin lugar a la indemnización de perjuicios que solicitaba el demandante porque no pudo probarse el conocimiento del mismo por parte del vendedor. La consideración determinante para concluir que el bien adolecía de vicio redhibitorio fue que por estar con gorgojo, no era de calidad corriente o regular ${ }^{20}$.

En otro caso, de 1884, la Corte de Santiago decretó la rescisión de un contrato de venta de una pareja de caballos, toda vez que uno de ellos adolecía de una enfermedad incurable llamada "galápago" que podía llegar a inutilizarlo, razón por la que el animal no servía o solo lo hacía imperfectamente para su uso natural ${ }^{21}$.

No hemos encontrado fallos colombianos sobre este tema. Aunque de todas formas podemos señalar que conforme a la jurisprudencia chilena, algunos factores externos, como plagas, o internos, como enfermedades de animales pueden comprometer la calidad del bien y por ello constituyen vicio redhibitorio. Los elementos concurrentes que hemos advertido en casos anteriores: la presencia del defecto y que por él la cosa no sirva o sirva imperfectamente, vuelven a presentarse, salvo en el caso que destacamos de las semillas agorgojadas donde se adopta un concepto de vicio meramente material, toda vez que en el análisis del fallo no aparece con claridad si por ello se afecta el uso del bien, sino tan solo que no tiene la calidad deseada.

\section{CASOS QUE NO CONSTITUYEN VICIOS REDHIBITORIOS}

En los puntos siguientes indicaremos algunos casos en los que se ha interpuesto una acción redhibitoria pero tanto los tribunales chilenos como colombianos, no han considerado que los defectos alegados constituyan vicio al no tratarse de defectos físicos

20 Correa con Salas hermanos (1882). En otro evento similar, también de venta de trigo afectado por gorgojo, se condenó a indemnización de perjuicios al vendedor, por considerar que era un agricultor, condición por la que debía conocer el vicio. Jiron con Holzmann (1886). De todas formas, cabe señalar que en estos casos, a diferencia de la mayoría de eventos donde se ha discutido la presencia de vicios redhibitorios, no advertimos en el análisis de los tribunales que estos hayan determinado que por la presencia del defecto se reduzca o impida el uso natural del bien, por lo que se trata de un concepto de vicio oculto meramente material.

21 El fallo de primera instancia había negado las pretensiones considerando que la situación no podía ser oculta para el comprador. Urrutia con Larraín (1884). En otro caso, se consideró también que la enfermedad de la que adolecen animales constituye vicio redhibitorio. El comprador de unos novillos interpuso acción redhibitoria más indemnización de perjuicios, alegando que estos estaban infectados. La sentencia de primera instancia rechazó la demanda. Dicho fallo fue revocado en apelación. La Corte Suprema confirmó el fallo del tribunal que había asumido, en aplicación del artículo 1864 del Código Civil, que al estar enfermos algunos de los novillos se destruía la unidad del lote. Igualmente consideró bien aplicado el artículo 1861 del Código Civil sobre indemnización pues se probó que el vendedor sabía o debía conocer que los animales vendidos estaban infectados. Izquierdo y otros con Urrutia (1953). En otro caso más reciente se interpuso acción redhibitoria de la venta de un animal por considerar que la enfermedad que este padecía (tuberculosis), constituye vicio redhibitorio porque por esa razón no podría destinarlo para el fin que era expenderlo al público. No se admitió la demanda por considerar que la acción no cabía contra el intermediario que había obrado en la venta. No obstante, no hubo consideraciones de fondo sobre el vicio alegado. Muñoz con Ferias Bio-Bio (1989). 
propios del bien que impidan o reduzcan su uso natural o porque se trata de supuestos de otras acciones ${ }^{22}$.

\section{IMPERFECCIONES QUE DESAGRADAN AL COMPRADOR}

En algunas causas se ha discutido si las imperfecciones presentes en el bien que desagradan al comprador constituyen vicio redhibitorio.

En Colombia se ha establecido que las imperfecciones que desagraden al comprador sin que impidan o disminuyan el uso de la cosa no constituyen vicio redhibitorio y por tanto tendrá el comprador que soportarlas, tal como lo señaló la Corte Suprema en un caso donde se concluyó que una servidumbre oculta por sí sola no constituye vicio redhibitorio ${ }^{23}$.

En el mismo sentido encontramos un fallo en Chile, a propósito de un caso en que el comprador demandó la rescisión del contrato de venta de un cargamento de arroz, alegando que este presentaba vicio redhibitorio porque estaba coloreado con azul de ultramar. En primera y segunda instancias se consideró que este hecho no era un vicio, toda vez que tal coloración no impedía el uso del bien ${ }^{24}$.

Podemos establecer a partir de lo anterior, que tanto para los tribunales chilenos como colombianos, los defectos o imperfecciones que solo desagraden al comprador y no afecten el uso natural, no constituyen vicio redhibitorio. Aunque se encuentra presente un defecto que constituye el factor material del vicio, este no es calificado como tal al no afectar el uso natural del bien, por lo que no se verifica el elemento funcional presente en la mayoría de casos analizados en la primera parte de este trabajo.

\section{DEFECTOS DE CANTIDAD, INTEGRIDAD Y EXTENSIÓN}

La pregunta que surge en este punto es si los defectos de cantidad pueden tener la categoría de vicio redhibitorio.

\footnotetext{
22 En algunos casos discutidos ante tribunales chilenos, aunque no se han presentado defectos en el bien, los demandantes han pedido la rescisión del contrato. En un caso, la vendedora pidió la rescisión por no pago del precio de parte del comprador y el Juez de primera instancia, en fallo confirmado en apelación consideró que la causal alegada no es un vicio redhibitorio que autorice la rescisión del contrato, sino un motivo para exigir el pago del precio o la resolución con indemnización de perjuicios. Riquelme con Williamson (1887). En otros eventos, tratándose de cesión de créditos incobrables o venta de acciones, se ha considerado que la no obtención de la utilidad esperada por causas inciertas tales como el pago del crédito cedido por el deudor o por factores económicos aleatorios como en la venta de acciones, no constituye en sí misma un vicio redhibitorio, sino más bien se deriva de la naturaleza aleatoria de la venta. Así, en los siguientes fallos: Díaz con Sindico Sociedad Garempangue (1878). Díaz con Mackenna (1879). Sermini con Martignoni (1882). Tersago con Ariztía (1926).

${ }^{23}$ Iregui con Cabal y Núñez (1969). Adicionalmente, en un caso de venta de un automóvil se demandó su reparación y en subsidio acción redhibitoria considerando que las fallas que presentaba el vehículo constituían un vicio oculto. El fallo de primera instancia acogió la pretensión subsidiaria, pero el tribunal de apelación determinó que el defecto alegado que era un ruido que producía el automóvil, no constituía vicio pues no impedía o reducía la posibilidad de uso del mismo y tampoco se podía saber si era o no anterior al contrato. La Corte Suprema confirmó la decisión del tribunal. Montoya y Márquez con Casa Británica (1993).

24 Delpino y Andrade con Hengstenberg y Compañia (1900).
} 
En el Derecho colombiano encontramos un caso en el que el comprador de una hacienda demandó la rescisión del contrato junto con la restitución del precio e indemnización de perjuicios, por no haber cumplido el vendedor con sus obligaciones basado entre otras en las normas sobre saneamiento por vicios ocultos y en subsidio resolución del mismo por incumplimiento. Después de recibida la hacienda, el comprador constató que en ella había muchos menos bienes (árboles, cafetales, etc.) que los indicados en el contrato y algunos en mal estado (como animales). La primera instancia decretó la rescisión del contrato, además de los perjuicios sufridos por el comprador. El fallo de segunda instancia consideró improcedente la acción rescisoria por vicios redhibitorios de las cosas vendidas, señalando que estos no se encontraban probados en el caso, además el mal estado de algunos de ellos era fácilmente perceptible. La Corte Suprema de Justicia estableció que los defectos de cantidad no constituyen vicios redhibitorios sino incumplimiento del contrato regido por las normas generales, por lo que decretó la resolución por incumplimiento. La Corte distinguió el saneamiento por vicios ocultos del incumplimiento del contrato derivado de faltar una parte considerable del bien, que da lugar al comprador a desistir del mismo mediante una acción resolutoria o a darlo por subsistente abonando el precio a justa tasación, conforme lo señala el artículo 1870 del Código Civil ${ }^{25}$.

Así, aunque no encontramos un caso similar que hubiese sido discutido por los tribunales chilenos, deducimos que en las faltas de cantidad, integridad y extensión del bien, no se verifica ni el elemento material ni el funcional para calificarlas como vicio redhibitorio, por lo tanto, se trata de un supuesto de otra acción, que como lo señaló el fallo citado, constituyen un supuesto de incumplimiento atacable conforme a las reglas generales.

\section{PROHIBICIONES O RESTRICCIONES PARA CONTRATAR}

En algunos casos ante la presencia de situaciones jurídicas que comprometan la libertad del vendedor para enajenar el bien, se han presentado demandas donde el comprador ha interpuesto acción redhibitoria, señalando que tal situación constituye un vicio.

Sobre esto se encuentra un caso fallado en Chile. El comprador demandó la rescisión de la venta alegando que el vehículo objeto del contrato adolecía de un vicio oculto consistente en su incautación por carabineros por internación ilegal. La Corte de apelaciones de Santiago revocó el fallo de primera instancia, negó la demanda y determinó que los vicios ocultos que tienen la calidad de redhibitorios se refieren a defectos físicos relacionados con la mala calidad de la cosa vendida y no a defectos jurídicos consistentes en posibles prohibiciones legales para contratar, situaciones que generan otras acciones como la nulidad ${ }^{26}$.

En el Derecho colombiano, encontramos un caso basado en una situación similar, aunque en el mismo se desechó la acción redhibitoria interpuesta por el comprador por

25 Para la Corte, la acción del artículo 1870 -equivalente al artículo 1814 C.C. chil.- es la misma resolutoria general por incumplimiento. Cuellar con Price (1899).

26 Flórez con Pérez (1988). 
considerar que existían dudas sobre si la situación alegada como "vicio", que consistía en que el vehículo fue retenido por la policía metropolitana de Cali porque sus sistemas de identificación presentaban irregularidades al haber sido injertados y movidos, había sido anterior o posterior al contrato 27 .

Lo que podemos deducir de estas interpretaciones, es que no constituye vicio redhibitorio que la enajenación del bien esté limitada, esta se encuentre restringida o esté prohibida en todo caso, pues ello no constituye un defecto físico que reduzca o impida su uso natural, de tal forma que no se verifican ni el factor material ni funcional que lo componen.

Además, la contravención de la prohibición para adquirir el bien que constituye supuesto de acción de nulidad por ilicitud en el objeto conforme a lo dispuesto en los artículos 1464 y 1682 C.C. chil., equivalentes al 1521 y 1741 C.C. col., y por tanto el comprador debe acudir a otras acciones para defender sus intereses.

\section{GRAVÁMENES Y LIMITACIONES DEL DOMINIO}

En ocasiones se ha interpuesto acción redhibitoria al considerar los demandantes que la presencia de gravámenes constituye un vicio que les impide el uso natural de la cosa.

Sobre esto encontramos un fallo chileno de 1864 a propósito de la demanda interpuesta por el comprador de un inmueble adquirido en un remate, quien con el fin de retractarse de la venta alegó la existencia de una hipoteca con la cual estaba gravado el fundo. El fallo de primera instancia reconoció el derecho del comprador a retractarse del contrato porque la escritura no había sido autorizada por escribano. La Corte de La Serena en apelación, consideró que no obstante no se había otorgado escritura de venta el rematante quedaba obligado por la postura y además la hipoteca a favor de tercero no constituye vicio redhibitorio, dando derecho al comprador para depositar el precio hasta que se otorgue la cancelación del gravamen, conforme al artículo 1872 C.C. chill ${ }^{28}$.

Igualmente la Corte de Temuco en fallo de 1936, señaló que “...una hipoteca no puede ser jamás un vicio oculto, dados los requisitos que señala el artículo 1858 del Código Civil, ya que no pueden constituir impedimentos para que el inmueble hipotecado sirva para su uso natural ..."29.

\footnotetext{
27 El comprador demandó la resolución del contrato de venta para que condenara al vendedor a "reintegrar" el vehículo o en su lugar a la devolución del precio con intereses y corrección monetaria e indemnización de perjuicios. El juzgado noveno civil de circuito de Cali acogió las pretensiones de la parte demandante. El Tribunal Superior de Distrito Judicial de Cali revocó el fallo. El Tribunal señaló que la sola probabilidad próxima o remota, previsible o no, de que el vicio pueda producirse con posterioridad al momento en que el riesgo se traslada al adquirente descarta el ejercicio de la acción resolutoria porque el vicio de la cosa es redhibitorio. La Corte Suprema no casó la sentencia. Maz - Autos con Carrillo (2001). Consideramos que en el caso debió analizarse si el hecho alegado por el comprador constituía en sí mismo un vicio que impedía o restringía el uso del bien, independientemente de si fue anterior o posterior al contrato.

28 Illanés con herederos de Chadwig (1864). La norma equivale al artículo 1929 C.C. col. En sentido similar sobre un caso análogo, Fuenzalida con Valdes (1879).

${ }^{29}$ Muñoz y otro con Véliz (1936).
} 
Adicionalmente, en un fallo de la Corte de Santiago de 1888, se determinó que la existencia de un censo sobre un bien no constituye vicio redhibitorio, puesto que este no intenta privar al comprador en todo o parte de la cosa, como si sucede con la existencia de una hipoteca o censo inscrito y además a lo que podrían dar lugar estos gravámenes es a una acción de saneamiento por evicción ${ }^{30}$.

También en Chile se ha señalado que no puede ser considerado vicio redhibitorio el que una franja del inmueble objeto de venta esté sometida a expropiación, toda vez que esta no constituye un defecto intrínseco del bien, además porque el comprador podría verificar tal situación mediante un estudio de títulos. Así se decidió en el siguiente caso: se celebró un contrato de permuta de inmuebles. Uno de ellos se encontraba sujeto a expropiación en una superficie de 56 metros cuadrados. El adquirente de este bien interpuso acción redhibitoria al considerar que este hecho constituía vicio redhibitorio.

El juez de primera instancia acogió la demanda y declaró la rescisión del contrato de permuta por considerar que el inmueble adjudicado adolecía de vicios redhibitorios. La Corte de Apelaciones de Valparaíso revocó el fallo y rechazó la acción. El argumento, ratificado por la Corte Suprema al conocer el recurso de casación, consistió básicamente en asumir que el estar una franja del inmueble sujeta a expropiación para construir una calle de servicio de la carretera, no es vicio redhibitorio por no constituir una "anomalía intrínseca" o un defecto, además porque tal situación pudo ser advertida al hacer el estudio de títulos ${ }^{31}$.

Por otra parte, la presencia de servidumbres ocultas que afecten un predio ha sido alegada en ocasiones ante los tribunales de Colombia y Chile, como constitutiva de vicio redhibitorio.

En Colombia se encuentra un caso en que la compradora de una casa demandó la rebaja de precio por vicio consistente en la existencia de una servidumbre de alcantarilla-

30 El caso estaba relacionado con la demanda intentada por un Convento beneficiario del censo, contra el comprador de un bien para que este pagara los réditos insolutos. El demandado requirió que su vendedor fuera obligado a cumplir con tal exigencia. El vendedor asumió su defensa señalando que en el contrato el comprador había renunciado al saneamiento por evicción y vicios ocultos. Indicó que al tratarse de vicios redhibitorios, el comprador no habría podido ignorar la existencia de los mismos. Además de insistir en que el supuesto no era de vicios redhibitorios sino de evicción, la renuncia a la misma no libraba de pagar el censo. El fallo de primera instancia fue confirmado en apelación. Convento de Santo Domingo con Montt (1888).

31 Se insistió en el fallo de apelación en que dicha situación podía y debía haber sido observada por el demandante antes de celebrar el contrato de permuta. Bustamante con Bruna (2003). En otro caso, el comprador demandó la rebaja del precio e indemnización de perjuicios, pues con posterioridad a la celebración del contrato se percató que los terrenos estaban afectos a una expropiación por lo que al intentar ejecutar un proyecto de construcción sobre el lote se le negó por las autoridades municipales, pues no se cumplía con una superficie predial mínima. El fallo de primera instancia rechazó la demanda al considerar que los vicios redhibitorios “...deben ser físicos inherentes a la cosa misma y de tal naturaleza que impidan que la cosa sirva para su uso natural o sirva imperfectamente...” (...) “...y no a posibles defectos jurídicos relacionados con eventuales prohibiciones o restricciones de orden legal, como ha ocurrido en la especie". La Corte de Apelaciones de Santiago confirmó el fallo y se negó a hacer mayores consideraciones, pues acogió la excepción de prescripción opuesta por el demandado. Finalmente, el recurrente desistió del recurso de casación en el fondo, lo que fue aceptado por la Corte Suprema. Rabinovich y Compañia Limitada con Empresa de los Ferrocarriles del Estado (2004). 
do, además de la indemnización de perjuicios de ello derivados y de la entrega tardía del bien. En fallo de primera instancia se condenó a la vendedora por la entrega tardía del inmueble pero se denegaron las demás peticiones. El Tribunal Superior de Distrito Judicial de Bogotá declaró en apelación que la servidumbre en cuestión si constituía vicio redhibitorio de la casa enajenada condenando a la rebaja del precio. Al resolver la casación, la Corte Suprema de Justicia negó que este caso constituyera vicio redhibitorio y consideró que se trataba de un defecto que no impedía la utilización de la $\cos ^{32}$.

En Chile también encontramos un caso en relación a una servidumbre oculta de acueducto. La Corte de Apelaciones de Santiago confirmó un fallo que acogió la pretensión del comprador y decretó la rebaja de precio, al considerar que la existencia en el inmueble comprado de una servidumbre conformada por una tubería y dos cámaras de registro que no fue manifestada por la vendedora, constituye un vicio redhibitorio, pues generaba para la compradora un riesgo de hundimiento de cierta parte del terreno del inmueble comprado, de forma que el bien solo servía imperfectamente para su uso natural ${ }^{33}$.

A partir de este fallo consideramos que cabe hacer la siguiente precisión: es cierto, conforme lo establecido en párrafos anteriores, que los gravámenes y limitaciones del dominio, por sí solos no constituyen vicio redhibitorio y así su presencia incomode al comprador del bien afectado por ellos, la naturaleza misma de tales limitaciones lleva a que quien detente la propiedad del bien deba soportarlas. De todas formas, las servidumbres que presentan defectos de construcción, constituye una excepción a tal regla en materia de gravámenes y limitaciones al dominio, dado que en este caso si se trata de defectos físicos que afectan la funcionalidad del bien y por tanto constituyen vicios para efectos de la acción redhibitoria ${ }^{34}$.

De lo anterior podemos deducir que para los tribunales chilenos y colombianos, la presencia de gravámenes en el bien constituidos a favor de terceros, no constituyen vicio redhibitorio pues no son defectos materiales que reduzcan o impidan el uso natural del bien, sino situaciones jurídicas que el titular del derecho de dominio del bien gravado debe soportar atendida la naturaleza jurídica de aquellos. Esto, sin perjuicio de la excepción advertida en punto de las servidumbres ocultas que por defectos de construcción afecten el uso natural del bien que las soporta, caso en el cual se considera un vicio redhibitorio puesto que se verifican los dos elementos que lo conforman: el defecto material y como consecuencia de él, la afectación funcional del bien.

\footnotetext{
32 Como vimos anteriormente, se insistió en que las imperfecciones que desagraden al comprador, sin que le impidan o limiten tal uso, no constituyen un vicio. Iregui con Cabal y Núñez (1969), cit., supra, nt. 23.

33 Correa con Inmobiliaria Los Andes S.A. (1999).

${ }^{34}$ Esto lo inferimos de las siguientes consideraciones del fallo: "En efecto, por la conformación de tales instalaciones es presumible pensar que si se produjera un anegamiento se inundaría el terreno con las aguas servidas de las casas vecinas; debe pagarse la manutención y reparación de las dos cámaras extras...”. También cabe señalar que ello, sin perjuicio de la responsabilidad que incumba al dueño del predio sirviente conforme a los artículos 923 del Código Civil colombiano y 82 del Código de Aguas en Chile, normas que dan derecho al dueño del predio sirviente a obtener la indemnización por los daños originados en la construcción de la servidumbre de acueducto, sus filtraciones, derrames imputables a defectos de construcción.
} 


\section{DERECHOS INEXISTENTES DEL VENDEDOR}

En algunos casos se ha discutido si la inexistencia de derechos del vendedor sobre el bien, constituye vicio redhibitorio.

En un caso fallado en Chile se discutió como vicio redhibitorio la no presencia de un camino en un terreno objeto de venta que según el comprador pertenecía al fundo. El comprador demandó la rebaja del precio aduciendo vicio redhibitorio al tiempo de la venta. Tanto el fallo de primera instancia como la sentencia de apelación de la Corte de Santiago, consideraron que la no existencia del camino no constituye vicio redhibitorio por lo que negaron la demanda 35 .

Otro fallo confirmado en apelación por la Corte de Talca en 1926, se refirió a los siguientes hechos: el adquirente de un fundo en remate judicial interpuso acción redhibitoria contra el primer vendedor (el bien había sido adquirido por ventas sucesivas). El vicio alegado consistía en que al momento de la venta original, el vendedor sabía que no podía extraer agua de un estero para regar el fundo. En primera instancia se determinó que al comprador no le cabía acción redhibitoria contra el primer vendedor, pues esta no se transmite, pero además que el vicio redhibitorio “...dice relación con defectos o irregularidades de la cosa misma y no con el derecho más o menos amplio que a ella pueda tener el vendedor..." 36 .

De la misma forma se ha considerado que el ser ajena la cosa, no constituye vicio redhibitorio.

Así se consideró en un caso en que el comprador de 220 hectáreas de montaña demandó al vendedor alegando que cuando fue a explotar la madera encontró que la hijuela designada por el vendedor no era de él sino del fisco, por lo que no pudo explotarla. El comprador pidió que se decretare la rebaja del precio de venta por vicio oculto. El fallo de primera instancia consideró que el hecho de no pertenecer al vendedor el todo o parte de la cosa vendida, no es un vicio que permita la acción redhibitoria ${ }^{37}$.

De conformidad con lo anterior, la regla que podemos deducir de las consideraciones hechas por los tribunales de Chile, es que los vicios redhibitorios no se refieren al derecho que sobre el bien pudiera tener el vendedor pues esto no es un defecto o irregularidad de la cosa misma. Además, en estos supuestos el comprador tiene distintas

\footnotetext{
35 Fórmas con Infante (1881).

36 Morel con Ibáñez (1926).

$37 \mathrm{La}$ Corte de apelaciones de Concepción confirmó el fallo. La Corte Suprema negó el recurso de casación. Casanueva con Faundes (1917). En un sentido similar, el fallo de primera instancia de 13 de abril de 1898, confirmado en apelación por la Corte de Valparaíso que negó la demanda de un comprador que alegaba la rescisión del contrato de venta de un negocio que el vendedor tenía establecido en una hacienda de la que a su vez era arrendatario. El vicio redhibitorio alegado por el demandante consistió en que después de celebrada la venta, descubrió que el vendedor del almacén no tenía la facultad de transferir o subarrendar el sitio en que estaba el negocio vendido, según contrato privado entre el vendedor del local y el administrador del fundo. En los considerandos 3 y 4 del fallo de primera instancia se señaló que dicha situación (la prohibición de subarrendar el local) no era un vicio redhibitorio que afectara las mercaderías objeto de la venta. Jeria con Martínez (1898). De todas formas, podemos considerar que no es del todo exacta esta última apreciación, pues el contrato no tuvo por objeto las mercaderías solamente, sino el establecimiento considerado como una unidad.
} 
defensas, como pueden ser: alegar las acciones por incumplimiento del contrato o el saneamiento por evicción, como en el caso de la venta de cosa ajena en que el verdadero propietario la reclamare judicialmente. A propósito de los casos anteriores, no hemos encontrado fallos de tribunales colombianos donde se hayan discutido temas similares.

\section{GRAVÁMENES Y DEFECTOS QUE AFECTAN OTROS BIENES}

En los tribunales de Chile se ha discutido si constituyen vicios redhibitorios los defectos de los inmuebles o vías colindantes al bien vendido, o que aquellos estén sometidos a gravámenes o sean objeto de expropiación.

Así por ejemplo, en un caso conocido en apelación por la Corte de Valparaíso en 1918. El comprador de un inmueble que fue demandado por el vendedor, quien interpuso acción resolutoria del contrato por incumplimiento del pago del precio, propuso reconvención para que se resolviera el contrato alegando la existencia de un vicio redhibitorio, puesto que con posterioridad a su perfección, se habían expropiado predios aledaños de forma que la casa quedó cercada y por tanto inútil e improductiva.

El juez de primera instancia acogió la demanda y rechazó la reconvención por considerar inaceptable la acción resolutoria sobre la base alegada y porque el vicio oculto no se encontraba justificado. La Corte de Apelaciones de Valparaíso confirmó el fallo y consideró que la existencia o inexistencia de deslindes no constituyen vicio redhibitorio, pues es un hecho verificable y observable al tiempo del contrato y principalmente “...porque tal hecho no importa una carga, vicio, tacha o defecto que haga que la cosa vendida no sirva para su uso natural o solo sirva imperfectamente..."38.

En otro caso similar, un comprador demandó la rescisión del contrato de venta de una casa porque esta no colindaba con una calle pública como creyó al contratar. La Corte de Santiago determinó que esto no constituye un vicio redhibitorio pues no hace que la cosa vendida no sirva para su uso natural o solo sirva imperfectamente ${ }^{39}$.

En Colombia se ha negado también el carácter de vicios ocultos a los defectos que no se originan en el predio objeto de venta, sino en bienes aledaños. Así se decidió en el siguiente caso: la compradora de una casa demandó la rebaja del precio e indemnización de perjuicios dado que con posterioridad a la entrega algunas paredes se empezaron a agrietar y se presentaron deformaciones en puertas, ventanas y hundimiento de pisos, por lo que la casa solo servía imperfectamente para habitarla. En primera instancia se desestimó la pretensión. El Tribunal Superior de Distrito Judicial de Bogotá confirmó el fallo considerando que los daños no se originaron en vicios ocultos de la casa sino en la deficiente construcción de un edificio contiguo ${ }^{40}$.

De lo anterior podemos inferir que tanto para los tribunales chilenos como colombianos, los defectos externos que no afecten directamente el bien objeto de la

\footnotetext{
38 Sociedad Población Vergara con Oliva (1918).

39 El fallo de primera instancia había fallado a favor del demandante señalando que tal situación si constituye vicio redhibitorio. La Corte de Santiago revocó la sentencia apelada por las razones señaladas. Caja de retiro de los ferrocarriles con Olivares (1928).

${ }^{40} \mathrm{La}$ Corte Suprema de Justicia confirmó el fallo del Tribunal. Melo con Barbosa (1968).
} 
venta, no constituyen vicio redhibitorio, porque además no reducen o inutilizan su uso natural.

\section{UN CASO DISCUTIDO: LA CALIDAD O SUSTANCIA DISTINTA A LA PACTADA}

Los casos que mencionamos en este punto los calificamos como discutidos, porque en ellos el debate ha consistido en si cuando los bienes no satisfacen al comprador porque no cumplen con la calidad esperada o la sustancia es distinta a la que se cree, adolecen de un vicio redhibitorio o constituyen más bien un supuesto de resolución por incumplimiento o nulidad por error en la calidad o sustancia (artículos 1510 y 1511 C.C. col.; 1453 y 1454 C.C. chil. $)^{41}$.

Así sucedió en el siguiente caso: se compró una casa en remate público solicitado por los albaceas y el heredero de la propietaria para cumplir con su testamento. El comprador demandó la rebaja del precio por vicios redhibitorios ya que en la tasación que hizo un agrimensor y que fue presentada por los albaceas, se afirmó que las paredes eran de cal y ladrillo cuando en realidad eran de ladrillo y barro; algunas de las paredes presentaban humedades y una de ellas carecía de simiento; los enmaderados que el tasador afirmaba ser de roble, eran de una madera de otra calidad llamada canelo. El fallo de primera instancia confirmado en apelación, consideró que con excepción de las humedades que podían ser advertidas al momento de la venta, los otros sí constituían vicios redhibitorios y decretó la rebaja del precio $^{42}$.

En otro caso el vendedor de unos muebles de alcoba demandó al comprador por incumplimiento en el pago del precio. Este propuso la excepción de falta o insuficiencia de título, puesto que los muebles no eran en su totalidad de la calidad convenida ya que esperaba que fueran de una madera llamada “jacarandá” y resultó que algunos de ellos habían sido fabricados con dicha madera y otros no, situación que advirtió y fue protes-

41 Incluso hay casos en que tratándose de defectos que afectan la utilidad del bien, los demandantes intentan ya sea como principal o subsidiaria, la acción redhibitoria o la acción de nulidad por error. Así por ejemplo en: Varela y otros con Servicio de Vivienda y Urbanización I Región (2007), cit., supra, nt. 12. En este caso la Corte Suprema determinó que el defecto de construcción no es constitutivo de error sino de vicio redhibitorio, toda vez que en el primero no se afecta la utilidad del bien. En su momento, ALESSANDRI en la doctrina chilena y PÉREZ en la colombiana, se pronunciaron acerca de las diferencias entre la acción redhibitoria por vicios y la de nulidad por error en la sustancia o calidad. Para ALESSANDRI (1918) p. 261, en el vicio el bien entregado es el mismo que las partes pactaron, mientras en la calidad o sustancia el bien es otro. PÉREZ (1957) pp. 397-398, por su parte, tras dedicar varios párrafos a plantear la duda concluyó señalando que en los casos dudosos el comprador podrá optar por la rescisión por error o por la acción redhibitoria y para evitar tropiezos procesales propuso acumularlas como principal y accesoria en la demanda. También en esa línea aunque sin profundizar en el análisis, GÓMEZ (2008) p. 99. Recientemente tanto autores chilenos como colombianos han vuelto a plantear interrogantes acerca de la naturaleza de la acción redhibitoria y a destacar las débiles fronteras con otras acciones de defensa del comprador insatisfecho por defectos de calidad del bien, como la nulidad por error. Cfr. Mantilla Y TERnERA (2008) pp. 299-326; CAPRILE (2008) pp. 561-602; BARAONA (2008) pp. 659-668.

42 Cabe aclarar que en este caso se estableció que las ventas voluntarias en subastas no están sometidas a la limitación del artículo 1865 C.C. chil., equivalente al 1922 C.C. col., que excluyen el saneamiento por vicios ocultos en las ventas forzadas hechas por autoridad de la justicia. Eguiren con Albaceas de Díaz (1865). 
tada al momento de entrega. El juzgado de Valparaíso consideró que la intención del comprador fue adquirir muebles que estuvieran fabricados con madera de cierta calidad, de forma que entre ellos debía haber armonía. Declaró probada la excepción sobre la base de los artículos 1858, 1860 y 1864 del Código Civil y señaló que los defectos de calidad de los bienes objeto del contrato, constituyen vicios redhibitorios ${ }^{43}$.

Hasta aquí podemos advertir que la línea jurisprudencial trazada por los tribunales chilenos en eventos en que la cosa no tiene la calidad o sustancia esperada, es que se trata de un vicio redhibitorio. De todas maneras consideramos que no queda claro si para los tribunales que han decidido estos fallos, pues en las consideraciones no son explícitos en ello, es la sola falta en la calidad o sustancia lo que constituye vicio o si por la misma se reduce o impide su uso natural, por lo que estimamos que para la calificación del vicio se orientan hacia una concepción meramente material y no funcional.

En otro caso, se discutió si constituye vicio redhibitorio que la cosa entregada sea distinta a la pactada. El comprador de un vehículo demandó a los vendedores alegando la nulidad del contrato por falta de consentimiento, dado que no le habían entregado el bien pactado sino otro distinto que además no funcionó. Como pretensiones subsidiarias planteó la resolución por incumplimiento en la obligación de entrega y redhibitoria por vicios ocultos. Los demandados presentaron reconvención por falta de pago de una parte del precio. El juez de primera instancia acogió la excepción de prescripción de las acciones demandas y decretó el pago reconvenido. La Corte de Apelaciones de Valparaíso revocó el fallo de primera instancia y estableció que el automóvil entregado por los vendedores no correspondía a la clase y tipo estipulado en el contrato, razón por la que dedujo que estos no habían cumplido con las obligaciones pactadas, circunstancia que bastaba para acoger la acción resolutoria que se interpuso como subsidiaria ${ }^{44}$.

En otro caso más reciente el demandante pidió la resolución del contrato por incumplimiento, al haberse entregado un bien (sal) con una concentración distinta a la pactada y en subsidio rescisión por vicios ocultos ${ }^{45}$.

\footnotetext{
43 Seckel con Pradel (1868). En la doctrina, Alessandri en su momento se opuso a esta solución considerando que se trataba de una situación constitutiva de error en la calidad generadora de nulidad y no de vicio redhibitorio. ALESSANDRI (1918) p. 262.

${ }^{4} 4$ Estableció en uno de sus considerandos: "Que las disposiciones del Código de Comercio, en que se fundan las alegaciones de los demandados y que sirven, también, de base a la sentencia apelada, no son aplicables a la cuestión debatida, porque esas leyes se refieren al caso de vicios redhibitorios, esto es, a defectos de calidad en la cosa entregada, pero siempre que esta corresponda específicamente a la cosa vendida; 4. Que cualquiera otra interpretación contraria conduciría a confundir dos situaciones jurídicas de un orden enteramente diverso regladas por leyes distintas; la acción redhibitoria, que procede de vicios ocultos de la cosa vendida, y la acción resolutoria, que nace del no cumplimiento de lo pactado en la forma y condiciones de la especie vendida; 5. Que en fuerza de estas consideraciones son inaceptables la reconvención y la excepción de prescripción opuestas por los demandados, ya que la primera supone dar por establecido que el contrato se cumplió perfectamente y la segunda se refiere a una situación distinta de la contemplada en este fallo". Esta interpretación fue confirmada por la Corte Suprema al resolver el recurso de casación en el fondo. Montané con Reiser y Petitbon y Cía. (1930).

45 Tanto en este caso como en el anterior, puede advertirse que para los demandantes tampoco resulta claro si el supuesto de hecho es constitutivo de vicio redhibitorio o si se trata de una situación de incumplimiento contractual e incluso nulidad por error, ante lo cual optan por interponer una pretensión principal y otra u otras subsidiarias.
} 
Tanto la sentencia de primera instancia como el fallo de apelación rechazaron la demanda. La Corte Suprema señaló que el haber entregado sal en una concentración distinta a la pactada es una cuestión que “...se encuentra tratada en el artículo 1.454 del Código Civil, referida al error de hecho que se produce cuando la sustancia o calidad esencial del objeto sobre el que versa el acto o contrato es diversa de lo que se cree" ${ }^{46}$.

No obstante, señaló que no se había demandado la nulidad sino la resolución del mismo, por lo que procedió a verificar si se trataba de una situación de incumplimiento por haberse entregado una cosa distinta a la pactada que no servía para lo que buscaba el comprador. Ante esto, consideró que “...de acuerdo a las disposiciones que reglamentan la institución de los vicios ocultos, ellas se aplican cuando entregada la cosa realmente vendida, esta resulta tener un vicio existente al tiempo de la venta, pero que no puede ser advertido por el comprador, lo que en este caso se cumple, como se encuentra establecido en autos. Pero ello solo puede tener lugar cuando la cosa entregada es realmente la vendida, lo que no acontece en autos, donde la cosa entregada es otra, como ha quedado establecido en la sentencia de primer grado" ${ }^{4}$.

Adicionó que al no cumplirse la exigencia fundamental para la procedencia de la acción redhibitoria, debía declararse la resolución del contrato por incumplimiento, conforme a la regla general del artículo 1.489 del Código Civil, dado que el vendedor entregó un producto distinto al comprado ${ }^{48}$.

Como podemos ver, estos dos últimos fallos se alejan de la interpretación señalada en los casos anteriores toda vez que se concluye que la entrega de una cosa con sustancia distinta a la pactada, no constituye vicio redhibitorio sino incumplimiento del contrato y parecería además, que no se descarta la procedencia de la acción de nulidad por error.

Así entonces y conforme lo señalamos, resulta discutible como constitutivo de vicio redhibitorio, el evento en que el comprador espera que los bienes estuvieren fabricados con determinados materiales o que estos sean de cierta calidad o sustancia y con posterioridad a la entrega resulta que la calidad es diferente a la pactada y por tanto el bien no sirve para el uso natural o esperado por el comprador. En algunos eventos, los tribunales han señalado que se trata de un vicio redhibitorio y en otros, de una situación de incumplimiento. Esto nos permite afirmar que en los casos de entrega con una sustancia o calidad distinta a la pactada la frontera entre la acción redhibitoria y las

46 Cecinas La Preferida S.A. con Sociedad Comercial Salinak Ltda. (2005). En la doctrina, también se pronuncian sobre este caso y la dificultad de marcar la frontera entre la acción redhibitoria y la resolución por incumplimiento Caprile (2008) p. 581 y en relación con posible convergencia con la acción de nulidad por error y también resolutoria por incumplimiento Baraona (2008) pp. 663-664.

${ }^{47}$ Ibidem.

48 Ibidem. Como podemos apreciar, en este fallo se descarta el estudio de la nulidad por error en la sustancia o calidad, no porque la Corte piense que no se verifique, sino simplemente porque el demandante no lo solicitó. En cuanto al segundo planteamiento, debería admitirse la posibilidad de constituir un vicio redhibitorio el evento en que el defecto que hace que el bien no sirva para el fin natural, sea que no se trata de la cosa que el comprador esperaba o que no tiene las calidades pactadas. Consideramos que este caso podría generar la alternativa para interponer tanto una acción redhibitoria como una acción por incumplimiento contractual en la obligación de entrega y aún de nulidad por error en la identidad de la cosa vendida (Artículos 1510 C.C. col.; 1453 C.C. chil.). 
acciones por incumplimiento o nulidad no está lo suficientemente demarcada, lo que a su vez genera la duda de si más bien no se trata de una concurrencia alternativa de acciones para el mismo supuesto, tema que no aparece claro en los fallos.

\section{CONCLUSIONES}

A lo largo del texto hemos intentado determinar la presencia de algunos lineamientos jurisprudenciales, a partir de la revisión de fallos dictados por los tribunales de Colombia y Chile para la calificación de "vicios" que sirvan de supuesto de hecho para generar la acción redhibitoria. De lo anterior, podemos destacar como conclusiones las siguientes:

a) Los tribunales de Colombia y Chile asumen de forma coincidente que el supuesto fundamental para considerar que el bien está afectado por un vicio, es que este se refiera a defectos físicos que pueden tener origen interno o externo y consistir en: defectos de composición, defectos de construcción y diseño, defectos de insuficiencia material, defectos de elaboración y envase, defectos de salubridad, defectos de descomposición o contaminación, que produzcan el efecto de impedir o reducir el uso natural o pactado del mismo.

b) Podemos destacar que ya sea por disposición legal (como en el caso del artículo 934 del Código de Comercio colombiano) o por interpretación judicial, el uso que se puede ver disminuido o impedido no solamente es el natural, considerado como aquel para el que normalmente se utiliza la cosa, sino también el pactado, entendido como el destino que pretende darle el comprador, siempre y cuando haya acuerdo expreso o tácito con el vendedor. Advertimos entonces, una ampliación del concepto original contenido en el Código Civil, tanto en Colombia como en Chile.

c) A partir de lo anterior podemos inferir que el concepto de vicio que sirve de supuesto para ser calificado como redhibitorio es funcional y consiste en defectos físicos de origen interno o externo por los cuales la cosa no sirva o sirva imperfectamente. Según este concepto, no se genera la acción redhibitoria por la sola presencia del defecto, sino porque a partir de ello se afecte el uso. Esta conclusión la derivamos, al advertir que es una constante en el análisis judicial tanto en Colombia como en Chile considerar que por el defecto se reduzca o impida el uso del bien. No obstante, hemos encontrado que en algunos fallos se considera que hay vicio por la sola presencia del defecto que compromete la calidad del bien, sin que sea claro en ellos que por dicha falta de calidad se impida o reduzca el uso, como sucedió en el caso de la venta de trigo agorgojado que ha sido fallada en dos ocasiones por los tribunales chilenos ${ }^{49}$. Lo propio podemos anotar a propósito de algunos de los casos que calificamos como discutidos, que es la entrega de una cosa con calidad diferente a la pactada, sin que quede claro en ellos si por dicho defecto se compromete el uso natural del bien ${ }^{50}$.

\footnotetext{
${ }^{49}$ Cfr. Correa con Salas hermanos (1882) y Jiron con Holzmann (1886), cit., supra, nt. 20.

${ }^{50}$ Eguiren con Albaceas de Díaz (1865); Seckel con Pradel (1868), cit., supra, nt. 42.
} 
d) Existen defectos que no impiden o reducen el uso natural de la cosa o que por tratarse de supuestos de otras acciones, no son calificados como redhibitorios, tales como las prohibiciones o restricciones para contratar; gravámenes y derechos limitados o inexistentes del vendedor; gravámenes en vías e inmuebles colindantes; defectos de cantidad, integridad y extensión. En este punto encontramos que la mayoría de los casos han sido fallados por tribunales chilenos, salvo los referidos a defectos y gravámenes en vías e inmuebles colindantes imperfecciones que no impiden o disminuyen el uso, donde hay fallos coincidentes de ambos países y finalmente sobre defectos de cantidad en que no encontramos fallos chilenos. En materia de servidumbres ocultas, hallamos una excepción consistente en que las mismas constituyen vicio redhibitorio cuando presentan defectos materiales de construcción que afectan la funcionalidad del bien. De todas formas podemos advertir que no existen diferencias interpretativas en este tipo de casos.

e) Existen algunos casos discutibles, como la entrega de una cosa con calidad o sustancia diferente a la pactada que bien podrían ser analizados desde la óptica de otras acciones, como la de nulidad por error en la calidad o en la sustancia, o incumplimiento por entrega de una cosa diferente. En los casos de entrega de una cosa con calidad o sustancia diferente a la pactada, en un primer momento se ha considerado por los tribunales chilenos que esto constituye vicio redhibitorio y posteriormente en dos fallos se ha concluido que lo que se genera es incumplimiento.

Consideramos que las fronteras entre estos supuestos están todavía por ser delimitadas por lo que cabría explorar si en definitiva se trata de eventos constitutivos de vicio redhibitorio, o más bien de error en la calidad o sustancia o incumplimiento, para que el comprador afectado interponga la acción que corresponda o incluso, si al concurrir el supuesto de hecho en todas las anteriores, a lo que nos enfrentamos es a una concurrencia de acciones sin que haya todavía claridad a nivel jurisprudencial ni doctrinal sobre ello. Por esto, se requiere una revisión doctrinal y jurisprudencial y eventualmente legislativa, con el fin de explorar la posible adecuación de los diferentes eventos bajo una misma acción que comprenda los defectos de calidad, cantidad e identidad del bien, o que se permita al comprador acudir alternativamente a la acción que prefiera.

\section{BIBLIOGRAFÍA CITADA}

Alessandri Rodríguez, Arturo (1918): De la compra-venta $i$ de la promesa de venta (Santiago, Imprenta litográfica Barcelona) t. 2², 1402 pp.

BARAONA GONZÁLEZ, Jorge (2008): "La acción redhibitoria como acción de nulidad", en: GuZmán Brito, Alejandro (edit.), Estudios de Derecho Civil III. Jornadas nacionales de Derecho Civil Valparaíso, 2007 (Santiago, LegalPublishing) pp. 659-668.

BOnivento FERnÁndeZ, José Alejandro (2004): Los principales contratos civiles y su paralelo con los comerciales (Bogotá, Librería del profesional, 16 a edic.) 809 pp.

CAPRILE BIERmann, Bruno (2008): "Las acciones del comprador insatisfecho: el cúmulo actual (ley de protección al consumidor, vicios redhibitorios, error sustancial, resolución por incumplimiento) y la tendencia al deber de conformidad en el Dere- 
cho Comparado", en: Mantilla Espinosa, Fabricio y Pizarro Wilson, Carlos (coords.), Estudios de Derecho Privado en homenaje al profesor Christian Larroumet (Santiago, Universidad Diego Portales, Fundación Fueyo, Universidad del Rosario) pp. 561-602.

CÁRdenas MejíA, Juan Pablo (2007): "La resolución por problemas de funcionamiento de la cosa en el derecho colombiano: el régimen interno -vicios ocultos y garantía mínima presunta- y el régimen de la compraventa internacional de mercaderías", en: Gaitán Martínez, José Alberto y Mantilla Espinosa, Fabricio (dirs.), La terminación del contrato. Nuevas tendencias del Derecho comparado (Bogotá, Universidad del Rosario) pp. 217-316.

GÓmez Estrada, César (2008): De los principales contratos civiles (Bogotá, Temis, $4^{\mathrm{a}}$ edic.) $545 \mathrm{pp}$.

GuZMÁn Brito, AlEjANDRO (2007): "Sobre la relación entre las acciones de saneamiento de los vicios redhibitorios y las acciones comunes de indemnización, con especial referencia a su prescripción”, Revista chilena de Derecho Privado, No 9, pp. 95-119.

Mantilla Espinosa; Fabricio; Ternera Barrios, Francisco (2008): "Las acciones del comprador insatisfecho en el Derecho colombiano: un problema de incertidumbre jurídica", en: MANTilla Espinosa, Fabricio y PiZARro Wilson, Carlos (coords.), Estudios de Derecho Privado en homenaje al profesor Christian Larroumet (Santiago, Universidad Diego Portales, Fundación Fueyo, Universidad del Rosario) pp. 299-326.

PÉREZ Vives, Álvaro (1957): Compraventa y permuta (Bogotá, Temis, 2a edic.), 602 pp.

RODRÍGUEZ FONNEGRA, Jaime (1960): De la compraventa y materias aledañas (Bogotá, Lerner, Bogotá) 1149 pp.

TAMAYO LOMBANA, Alberto (2004): El contrato de compraventa, su régimen civil y comercial (Bogotá, Ediciones Doctrina y Ley Ltda.) 332 pp.

VAlencia ZEA, Arturo (1985): Derecho civil, contratos (Bogotá, Temis, 6a edic.) t. IV, $487 \mathrm{pp}$.

VéLEZ, Fernando (1926): Estudio sobre el Derecho Civil colombiano (París, Imprenta París - América, 2a edic., corregida y aumentada por Luis Ángel Arango) t. VII, 478 pp.

\section{NORMAS CITADAS}

\section{CHILE:}

Código Civil: artículos 1453, 1454, 1464, 1489, 1682, 1837, 1857, 1858, 1860, 1861, $1864,1865$.

Código de Comercio: artículo 154.

Decreto con fuerza de Ley 1.122, fija texto del Código de Aguas, Diario Oficial, 29 de octubre de 1981: artículo 82.

Ley 19.496, normas sobre protección de los derechos de los consumidores, Diario Oficial, 7 de marzo de 1997. 


\section{COLOMBIA:}

Constitución Política, Gaceta Constitucional 127 del jueves 10 de octubre de 1991: artículo 234.

Ley 57 de 1887 sobre adopción de códigos y unificación de la legislación nacional: Código Civil, Diarios oficiales núms., 7019, 7020 y 7021 del 20, 21, 22 de abril de 1887: artículos 923, 1510, 1511, 1521, 1741, 1870, 1872, 1893, 1914, 1915, 1922.

Decreto 410 de 1971 por el cual se expide el Código de Comercio, Diario Oficial № 33.339 del 16 de junio de 1971: artículos 870, 934.

Decretos 1400 y 2019 de 1970 por los cuales se expide el Código de Procedimiento Civil, Diario Oficial No 33.150 del 21 de septiembre de 1970: artículo 25.

\section{JURISPRUDENCIA CITADA}

\section{COLOMBIA}

Barrera con Rojas (1945): Corte Suprema de Justicia, Sala de Casación Civil, 6 de marzo de 1945 (acción estimatoria e indemnizatoria), Gaceta Judicial, tomo LVIII (1945), p. 638.

Corte Constitucional, Sentencia C- 836 de 2001 (acción de inconstitucionalidad contra el art. 4 de la Ley 169 de 1896), en DVD - Rom, Colección Jurisprudencial en DVD, RSJ, Bogotá, 2009.

Cuellar con Price (1899): Corte Suprema de Justicia, Sala de Casación Civil, 5 de julio de 1899 (acción redhibitoria e indemnizatoria), Gaceta Judicial, tomo IX (1900), $\mathrm{n}^{\circ}$ 436, p. 273.

Harinera del Valle con Imocon (2005): Corte Suprema de Justicia, Sala de Casación Civil, 14 de enero de 2005 (acción resolutoria por incumplimiento e indemnizatoria), exp. 7524, en DVD - Rom, Colección Jurisprudencial en DVD, RSJ, Bogotá, 2009.

Industria panificadora El Arbolito con Weston (1991): Corte Suprema de Justicia, Sala de Casación Civil, 11 de septiembre de 1991 (acción de declaración de incumplimiento, resolutoria e indemnizatoria), Gaceta Judicial, tomo CCXIII (1991), $\mathrm{n}^{\circ}$ 2451, p. 120.

Iregui con Cabal y Núñez (1969): Corte Suprema de Justicia, Sala de Casación Civil, 25 de marzo de 1969 (acción estimatoria e indemnizatoria), Gaceta Judicial, tomo CXXIX (1969), n 2306, 2307 y 2308, p. 10.

M.R. Inversiones con Cooperativa agropecuaria del Meta (1986): Corte Suprema de Justicia, Sala de Casación Civil, 23 de julio de 1986 (acción estimatoria e indemnizatoria), Gaceta Judicial, tomo CLXXXIV (1986), No 2423, p. 120.

Manssur y Abdala con Hernández y Hernández (1988): Corte Suprema de Justicia, Sala de Casación Civil, 12 de agosto de 1988 (acción redhibitoria e indemnizatoria), Gaceta Judicial, tomo CXII (1988), No 2431, p. 65.

Maz - Autos con Carrillo (2001): Corte Suprema de Justicia, Sala de Casación Civil, 5 de abril de 2001 (acción resolutoria por incumplimiento e indemnizatoria), exp. 5897, en DVD - Rom, Colección Jurisprudencial en DVD, RSJ, Bogotá, 2009. 
Melo con Barbosa (1968): Corte Suprema de Justicia, Sala de Casación Civil, 15 de octubre de 1968 (acción estimatoria e indemnizatoria), (sin publicar en la Gaceta Judicial).

Montoya y Márquez con Casa Británica (1993): Corte Suprema de Justicia, Sala de Casación Civil, 9 de agosto de 1993 (acción de cumplimiento e indemnizatoria), exp. 3727, Gaceta Judicial, tomo CCXXV (1993), No 2464, p. 314.

Rodríguez con Gutiérrez (1977): Corte Suprema de Justicia, Sala de Casación Civil, 11 de octubre de 1977 (acción redhibitoria e indemnizatoria), (sin publicar en la Gaceta Judicial).

Salcedo con Muñoz y Droguería Jaramillo (1955): Corte Suprema de Justicia, Sala de Casación Civil, 23 de junio de 1955 (acción redhibitoria e indemnizatoria), Gaceta Judicial, tomo LXXX (1956), n 2153, p. 452.

Vergara con Caja de Crédito Agrario Industrial y Minero (1999): Corte Suprema de Justicia, Sala de Casación Civil, 18 de noviembre de 1999 (acción indemnizatoria por vicios ocultos), exp. 5103 sentencia 092, Gaceta Judicial, tomo CCLXI volumen II (1999), No 2500, p. 1011.

Vergara y Abadia con Izquierdo e Izquierdo (1943): Corte Suprema de Justicia, Sala de Casación Civil, 6 de septiembre de 1943 (acción estimatoria e indemnizatoria), Gaceta Judicial, tomo LVI (1943), p. 95.

\section{CHILE}

Aravena con Comercial Rupanco Limitada; Inversiones San Ignacio S.A. (2007): Corte de Apelaciones de Rancagua, 21 de enero de 2007 (acción redhibitoria), Rol 828 2007, No LegalPublishing: 38231.

Burgos con Strakoch y Sohn (1914): Corte de Valparaíso, 31 de octubre de 1914 (acción redhibitoria e indemnizatoria), Gaceta de los Tribunales, $2^{\circ}$ sem., No 484 (1914), p. 1330.

Bustamante con Bruna (2003): Corte Suprema, 1 de octubre de 2003 (acción redhibitoria), Revista de Derecho y Jurisprudencia, tomo 100 (2003), 2a parte, sección 1a, p. 184.

Caja de retiro de los ferrocarriles con Olivares (1928): Corte de Santiago, 23 de junio de 1928 (acción rescisoria e indemnizatoria), Gaceta de los Tribunales, $1^{\mathrm{er}}$ sem., $\mathrm{n}^{\circ} 163$ (1928), p. 715.

Casanueva con Faundes (1917): Corte Suprema, 27 de diciembre de 1917 (acción de saneamiento por evicción), Revista de Derecho y Jurisprudencia, tomo 15 (1918), sección $1^{\mathrm{a}}$, p. 338.

Cecinas La Preferida S.A. con Sociedad Comercial Salinak Ltda. (2005): Corte Suprema, 27 de julio de 2005 (acción resolutoria e indemnizatoria), Rol 5320- 2003, No LegalPublishing : 32452 .

Convento de Santo Domingo con Montt (1888): Corte de Santiago, 14 de mayo de 1888 (acción de reconocimiento de un censo), Gaceta de los Tribunales, nº 713 (1888), p. 571. 
Correa con Inmobiliaria Los Andes S.A. (1999): Corte de Santiago, 1 de septiembre de 1999 (acción redhibitoria), Rol 7279 - 1997, No Legal Publishing: 20775.

Correa con Salas hermanos (1882): Corte de Santiago, 29 de mayo de 1882 (acción redhibitoria), Gaceta de los Tribunales, n 1.039 (1882), p. 605.

Delpino y Andrade con Hengstenberg y Compañia (1900): Corte de Valparaíso, 22 de octubre de 1900 (acción redhibitoria e indemnizatoria), Gaceta de los Tribunales, tomo 2, $\mathrm{n}^{\circ} 1.794$ (1900), p. 832.

Díaz con Mackenna (1879): Corte de Santiago, 7 de abril de 1879 (acción de nulidad), Gaceta de los Tribunales, $\mathrm{n}^{\circ} 324$ (1879), p. 208.

Díaz con Sindico Sociedad Garempangue (1878): Corte de Apelaciones de Santiago, segunda sala, sentencia 4453, 4 de marzo de 1878 (acción de rescisión), Gaceta de los Tribunales, No 4453 (1878), p. 1866.

Eguiren con Albaceas de Díaz (1865): Corte de Santiago, 2 de agosto de 1865 (acción estimatoria e indemnizatoria), Gaceta de los Tribunales, $n^{\circ} 1.569$ (1865), p. 632.

Flórez con Pérez (1988): Corte de Santiago, 10 de marzo de 1988 (acción redhibitoria), Revista de Derecho y Jurisprudencia, tomo 85 (1988), 2a parte, sección 2a, p. 18.

Fórmas con Infante (1881): Corte de Santiago, 28 de junio de 1881 (acción estimatoria e indemnizatoria), Gaceta de los Tribunales, No 994 (1881), p. 617.

Franjola con Carvallo (1944): Corte Suprema, 13 de enero de 1944 (acción indemnizatoria), Revista de Derecho y Jurisprudencia, tomo 42 (1945), 2a parte, sección 1a, p. 25.

Fuenzalida con Valdes (1879): Corte de Santiago, 23 de septiembre de 1879 (acción redhibitoria), Gaceta de los Tribunales, No 1.473 (1879), p. 1023.

Gaceta de los Tribunales, $2^{\circ}$ sem., $\mathrm{n}^{\circ} 16$ (1926), p. 86.

Illanés con herederos de Chadwig (1864): Corte de La Serena, 5 de abril de 1864 (acción de retracto de un remate), Gaceta de los Tribunales, n 1.685 (1864), C.3, p. 607.

Importadora Exportadora JYC Ltda. con Comercial Cisandina Chile Ltda. (2005): Corte Suprema, 14 de marzo de 2005 (acción ejecutiva), Rol 546-2004, No LegalPublishing: 31860 .

Inversiones y Negocios S.A.; Empresa Administradora de Créditos S.A. con Madison Inmobiliaria S.A. (2008): Corte Suprema, 3 de abril de 2008 (acción de declaración de incumplimiento e indemnizatoria), Rol 211-2008, $\mathrm{n}^{\circ}$ LegalPublishing: 38750.

Izquierdo y otros con Urrutia (1953): Corte Suprema, 30 de mayo de 1953 (acción redhibitoria e indemnizatoria), Revista de Derecho y Jurisprudencia, tomo 50 (1953), $2^{\text {a }}$ parte, sección $1^{\mathrm{a}}$, p. 173.

Jara y otros con San Francisco Ltda. (2007): Corte Suprema, 27 de noviembre de 2007 (acción indemnizatoria), Rol 2265-2006, No LegalPublishing: 37855.

Jeria con Martínez (1898): Corte de Valparaíso, 31 de octubre de 1898 (acción redhibitoria e indemnizatoria), Gaceta de los Tribunales, tomo II, nº 449 (1898), p. 403.

Jiron con Holzmann (1886): Corte de Santiago, 4 de diciembre de 1886 (acción redhibitoria e indemnizatoria), Gaceta de los Tribunales, $n^{\circ} 3.748$ (1886), p. 2398.

Larzabal con Sociedad Inmobiliaria Talasia Ltda. (2008): Corte Suprema, 27 de marzo de 2008 (acción indemnizatoria), Rol 6700-06, Microiuris. 
Montané con Reiser y Petitbon y Cía. (1930): Corte Suprema, Cas. forma 27 de octubre de 1928; Cas. fondo, 29 de marzo de 1930 (acción redhibitoria), Revista de Derecho y Jurisprudencia, tomo 27 (1930), sección 1a, p. 777.

Morel con Ibáñez (1926): Corte de Talca, 22 de abril de 1926 (acción indemnizatoria), Gaceta de los Tribunales, $1^{\mathrm{er}}$ sem., $\mathrm{n}^{\circ} 62$ (1926), p. 271.

Muñoz con Ferias Bio-Bio (1989): Corte de Concepción, 3 de abril de 1989 (acción redhibitoria), Revista de Derecho y Jurisprudencia, tomo 86 (1989), 2a parte, sección $2^{\mathrm{a}}$, p. 12.

Muñoz y otro con Véliz (1936): Corte de Temuco, 11 de marzo de 1936 (acción de saneamiento por evicción), Revista de Derecho y Jurisprudencia, tomo 33 (1936), 2a parte, sección 2a , p. 33.

Ojeda con Mackin (1887): Corte de Santiago, 22 de junio de 1887 (acción redhibitoria e indemnizatoria), Gaceta de los Tribunales, $\mathrm{n}^{\circ} 1.292$ (1887), p. 778.

Plaza con Astorga (1879): Corte de Santiago, 3 de mayo de 1879 (acción redhibitoria), Gaceta de los Tribunales, $\mathrm{n}^{\circ} 432$ (1879), p. 288.

Politoff con Sociedad Inmobiliaria Ingeco (1998): Corte de Apelaciones de Santiago, 17 de abril de 1998 (acción estimatoria e indemnizatoria), Rol 5676-1996, No LegalPublishing: 20595.

Rabinovich y Compañia Limitada con Empresa de los Ferrocarriles del Estado (2004): Corte Suprema, 14 de junio de 2004 (acción estimatoria e indemnizatoria), Rol 2189-2003, No LegalPublishing: 30322.

Riquelme con Williamson (1887): Corte de Santiago, 5 de mayo de 1887 (acción redhibitoria e indemnizatoria), Gaceta de los Tribunales, No 808 (1887), p. 472.

Rocha con Salinas y Fabres S.A. (2007): Corte de Apelaciones de Antofagasta, 29 de junio de 2007 (acción de reposición e indemnizatoria), Rol 49-2007, No LegalPublishing: 36578.

Rubio con Besa y Compañia (1915): Corte de Santiago, 12 de enero de 1915 (acción ejecutiva), Gaceta de los Tribunales, ${ }^{\mathrm{er}}$ sem., No 123 (1915), p. 278.

Seckel con Pradel (1868): Juzgado de Valparaíso, 9 de julio de 1868 (acción ejecutiva), Gaceta de los Tribunales, $\mathrm{n}^{\circ} 2.071$ (1868), p. 918.

Sermini con Martignoni (1882): Corte de Santiago, 24 de octubre de 1882 (acción ejecutiva), Gaceta de los Tribunales, nº 2.735 (1882), p. 1535.

Sociedad Población Vergara con Oliva (1918): Corte de Valparaíso, 7 de diciembre de 1918 (acción resolutoria), Gaceta de los Tribunales, 2ºm., nº 655 (1918), p. 2053.

Solar con Lyon (1883): Corte de Santiago, 16 de abril de 1883 (acción redhibitoria e indemnizatoria), Gaceta de los Tribunales, nº 700 (1883), p. 369.

Spataris con Sociedad Comercial Automotriz La Portada; Luna (2007): Corte Suprema, 25 de julio de 2007 (acción estimatoria e indemnizatoria), Rol 6658-2005, No Legal Publishing: 36814.

Tersago con Ariztía (1926): Corte Suprema, 17 de septiembre de 1926 (acción resolutoria),

Toledo con Sazy (1861): Juzgado de Santiago, 17 de abril de 1861 (acción redhibitoria e indemnizatoria), Gaceta de los Tribunales, ${ }^{\circ} 1318$ (1861), p. 574. 
Urrutia con Larrain (1884): Corte de Santiago, 19 de agosto de 1884 (acción redhibitoria), Gaceta de los Tribunales, n 2030 (1884), p. 1244.

Valencia con Merry del Val (1932): Corte de Santiago, 19 de marzo de 1932 (acción redhibitoria), Revista de Derecho y Jurisprudencia, tomo 29 (1932), secc. 2a, p. 78.

Varela y otros con Servicio de Vivienda y Urbanización I Región (2007): Corte Suprema, 24 de mayo de 2007 (acción de nulidad e indemnizatoria), Rol 3140-05, Microiuris.

Vergara con Inversiones Andalién S.A. (2002): Corte Suprema, 11 de abril de 2002 (acción redhibitoria), Rol 986-2001, No LegalPublishing: 24168.

Vidal con Marcoleta (1882): Corte de Santiago, 21 de junio de 1882 (acción resolutoria), Gaceta de los Tribunales, $\mathrm{n}^{\circ} 1.257$ (1882), p. 731.

Viollier Velasco, Fernando con Agricamex Ltda. (1996): Corte de Santiago, 17 de diciembre de 1996 (acción de declaración de incumplimiento e indemnizatoria), Revista de Derecho y Jurisprudencia, tomo 93 (1996), 2a parte, sección 2a , p. 133. 
